\title{
The Relationship Between Dopamine Synthesis Capacity and Release: Implications for Psychosis
}

\author{
Matthew M Nour*,I, Robert McCutcheon' and Oliver D Howes ${ }^{1,2}$ \\ 'Psychiatric Imaging, Department of Psychosis Studies, Institute of Psychiatry Psychology and Neuroscience, King's College London, London, UK; \\ ${ }^{2}$ MRC London Institute of Medical Sciences, Hammersmith Hospital Campus, London, UK
}

Neuropsychopharmacology (2018) 43, I195-I 196; doi:10.1038/npp.2017.293

Berry and colleagues report that presynaptic striatal dopamine synthesis capacity (measured with $\left[{ }^{18} \mathrm{~F}\right] \mathrm{FMT}$ PET) is not associated with methylphenidate-induced striatal dopamine release (indexed as a reduction in $\left[{ }^{11} \mathrm{C}\right]$ raclopride nondisplaceable binding-potential) in healthy participants (Berry et al, 2017). The authors should be commended for the quality of this study, in which 40 subjects each received three PET scans within a short time window. The results are pertinent to the interpretation of neuroimaging studies investigating the dopamine hypothesis of schizophrenia.

Multiple lines of evidence indicate that presynaptic striatal dopamine dysfunction is central to the pathoetiology of schizophrenia. Striatal dopamine synthesis capacity (also interpreted as dopamine turnover) is elevated in patients compared with healthy participants (Howes et al, 2012). Moreover, patients show exaggerated striatal dopamine release in response to $0.3 \mathrm{mg} / \mathrm{kg}$ intravenous amphetamine (measured with $\left.\left.\left[{ }^{123} \mathrm{I}\right] \mathrm{IBZM}\right]-\mathrm{SPECT}\right)(\mathrm{Abi}-\mathrm{Dargham}$ et al, 1998). A parsimonious hypothesis is that these findings represent two facets of the same underlying presynaptic dopamine dysfunction in schizophrenia. Thus, the lack of a relationship between dopamine synthesis capacity and methylphenidate-induced dopamine release in healthy participants warrants further consideration.

In contrast to the study of Berry and colleagues, the majority of PET/SPECT studies investigating dopamine synthesis capacity and release in schizophrenia used $\left[{ }^{18} \mathrm{~F}\right]$ DOPA or $\left[{ }^{11} \mathrm{C}\right] \mathrm{DOPA}$, and amphetamine challenge (AbiDargham et al, 1998; Howes et al, 2012). As the authors note, FMT and DOPA are sensitive to different aspects of presynaptic dopamine function. Moreover, amphetamine and methylphenidate promote dopamine efflux via divergent mechanisms. Whereas both stimulants block the presynaptic dopamine transporter (DAT), recent studies using fast-scan cyclic voltammetry in freely moving rats suggest that amphetamine $(1 \mathrm{mg} / \mathrm{kg})$ causes dopamine release via action potential-dependent mechanisms. These include increased

*Correspondence: Dr MM Nour, Department of Psychosis Studies, Institute of Psychiatry Psychology and Neuroscience, King's College London, PO63 Level 5, 16 De Crespigny Park, London, SE5 8AF, UK, Tel: +44 207848 0355, E-mail: matthew.nour@kcl.ac.uk frequency, amplitude and duration of spontaneous dopamine transients, which ride on-top of a more sustained dopamine accumulation (Covey et al, 2016; Daberkow et al, 2013). At this dose amphetamine also augments phasic dopamine responses to reward-predicting cues, whilst at higher doses $(5 \mathrm{mg} / \mathrm{kg})$ it decouples dopamine burst firing from behaviorally relevant cues, with a corresponding breakdown in goal-directed behavior (Daberkow et al, 2013). At high cytoplasmic concentrations, as can be achieved in brain-slice preparations, amphetamine also causes redistribution of vesicular dopamine and reversal of DAT.

Amphetamine-induced dopamine release in vivo, therefore reflects the sensitivity and capacity of presynaptic dopamine neurons to increase spontaneous transients under taskneutral conditions (Covey et al, 2016; Daberkow et al, 2013), in a way that methylphenidate-induced release does not. It has been proposed that this sensitivity under amphetamine may correlate with a more general tendency towards spontaneous dopamine transients in the drug-free state (Maia and Frank, 2017). This would result in increased presynaptic dopamine turnover, and manifest as a positive relationship between PET measures of dopamine synthesis capacity and amphetamine-induced dopamine release, but not methylphenidate-induced release, which may be more dependent on DAT function. Interestingly, one study in advanced Parkinson's Disease patients reported a positive correlation between putamen $\left[{ }^{18} \mathrm{~F}\right] \mathrm{DOPA}$ uptake and methamphetamine-induced dopamine release $\left(R^{2}=0.69\right.$ 0.74) (Piccini et al, 2003).

Under this hypothesis, the findings of increased dopamine synthesis and amphetamine-induced release capacity in schizophrenia may indeed reflect a single underlying abnormality, namely increased phasic dopaminergic responses to behaviorally-irrelevant cues, as proposed by the aberrant salience hypothesis (Howes and Nour, 2016; Kapur, 2003). Future PET studies that measure dopamine synthesis and amphetamine-induced release capacity in patients and healthy controls are necessary to test this hypothesis. 
1196

\section{FUNDING AND DISCLOSURE}

MMN is supported by the National Institute for Health Research, UK. RM is supported by the Wellcome Trust, UK. $\mathrm{ODH}$ is supported by the Medical Research Council, UK. The authors have no conflicts of interest in relation to this letter.

\section{REFERENCES}

Abi-Dargham A, Gil R, Krystal J, Baldwin RM, Seibyl JP, Bowers M et al (1998). Increased striatal dopamine transmission in schizophrenia: Confirmation in a second cohort. Am J Psychiatry 155: 761-767.

Berry AS, Shah VD, Furman DJ, White RL, Baker SL, O'Neil JP et al (2017). Dopamine synthesis capacity is associated with D2/3 receptor binding but not dopamine release. Neuropsychopharmacology (this issue).

Covey DP, Bunner KD, Schuweiler DR, Cheer JF, Garris PA (2016). Amphetamine elevates nucleus accumbens dopamine via an action potential-dependent mechanism that is modulated by endocannabinoids. Eur J Neurosci 43: 1661-1673.

Daberkow DP, Brown HD, Bunner KD, Kraniotis SA, Doellman MA, Ragozzino ME et al (2013). Amphetamine paradoxically augments exocytotic dopamine release and phasic dopamine signals. J Neurosci 33: 452-463.

Howes OD, Kambeitz J, Kim E, Stahl D, Slifstein M, Abi-dargham A et al (2012). The nature of dopamine dysfunction in schizophrenia and what this means for treatment. meta-analysis of imaging studies. Arch Gen Psychiatry 69: 776-786.

Howes OD, Nour MM (2016). Dopamine and the aberrant saience hypothesis of schizophrenia. World Psychiatry 15: 3-4.

Kapur S (2003). Psychosis as a state of aberrant salience: a framework linking biology, phenomenology and pharmacology in schizophrenia. Am J Psychiatry 160: 13-23.

Maia TV, Frank MJ (2017). An integrative perspective on the role of dopamine in schizophrenia. Biol Psychiatry 81: 52-66.

Piccini P, Pavese N, Brooks DJ (2003). Endogenous dopamine release after pharmacological challenges in Parkinson's disease. Ann Neurol 53: 647-653. 